\title{
Cross-cultural adaptation of the Brazilian version of the Dentine Hypersensitivity Experience Questionnaire (DHEQ-15)
}

\section{Dhelfeson Willya DOUGLAS-DE-OLIVEIRA ${ }^{(a)}$ Frederico Santos LAGES(a) Saul Martins PAIVA(a) Jennifer Grace CROMLEY(b) Peter Glenn ROBINSON(c) Luís Otávio Miranda COTA ${ }^{(a)}$}

(a) Universidade Federal de Minas Gerais UFMG, School of Dentistry, Belo Horizonte, $M G$, Brazil.

(b) University of Illinois, College of Education, Champaign, IL, USA.

(c) University of Bristol, Bristol Dental School, Bristol, UK.

Declaration of Interest: The authors certify that they have no commercial or associative interest that represents a conflict of interest in connection with the manuscript.

Corresponding Author:

Luís Otávio Miranda Cota

E-mail: luiscota@ufmg.br

hitps://doi.org/10.1590/1807-3107bor-2018.vol32.0037

Submitted: October 21, 2017

Accepted for publication: March 13, 2018

Last revision: March 15, 2018

\begin{abstract}
The dentine hypersensitivity (DH) is able to impair the oral health related quality of life (OHRQoL). However, there isn't any specific validated questionnaire to be used in Brazil. The objective was to adapt and to validate the English version of the Dentine Hypersensitivity Experience Questionnaire (DHEQ-15) for use in Brazil. DHEQ-15 was cross-culturally adapted into the Brazilian-Portuguese language and then validated in a cross-sectional study with 100 participants recruited at a University clinic. Study sample comprised 2 groups: 100 individuals with $\mathrm{DH}$, and 100 individuals without. The instrument was self-administered twice 7 to 10 days apart. The participants answered a global rating of oral health. The psychometric properties of the Brazilian version of DHEQ-15 were verified through internal consistency (Cronbach's $\alpha$ ) and test-retest reliability (intraclass correlation coefficient - ICC), convergent (Spearman correlation) and discriminant (Mann-Whitney test) validity. The significance threshold was set at $\mathrm{p}<0.05$. Sample comprised 69 men and 131 women, of mean age 30.4y. The Brazilian DHEQ-15 demonstrated very good internal consistency $(\alpha=0.945)$. Test-retest reliability revealed excellent reproducibility (ICC $=0.959, \mathrm{p}<0.001$ ). There was statistically significant correlation between the scores obtained on all DHEQ-15 domains and the global rating of oral health $(p<0.001)$. Participants with DH scored significantly higher than those without DH $(p<0.001)$. This study provides evidence supporting the cross-cultural validity of the Brazilian version of DHEQ-15 for use in Brazil.
\end{abstract}

Keywords: Dentin Sensitivity; Quality of Life; Surveys and Questionnaires.

\section{Introduction}

Dentine hypersensitivity (DH) is characterized by short and sharp pain arising from exposed dentine in response to thermal, evaporative, tactile, or osmotic stimuli that cannot be attributed to any other disease. ${ }^{1}$ Many at-home or in-office approaches have been proposed in order to treat $\mathrm{DH}^{2,3}$ $\mathrm{DH}$ is a common clinical problem with prevalence ranging from $3 \%$ to $98 \%$ in the European population, ${ }^{2}$ and from $17 \%$ to $46 \%$ among Brazilians. ${ }^{3,4,5}$

$\mathrm{DH}$ is an uncomfortable condition that affects function and quality of life. ${ }^{6}$ The Oral Health-Related Quality of Life (OHRQoL) is the patient's own perception of how the state of the mouth impacts upon his or her quality 
of life.7 People with DH may experience impacts on quality of life in everyday activities, such as eating, drinking, and social interaction, as well as more subtle impact on emotions and identity. ${ }^{1,89}$ A condition specific instrument may provide insights into the particular consequences of that condition without the background noise of impacts from other conditions. ${ }^{10}$

Since it was reported that one generic instrument (Oral Health Impact Profile, OHIP) did not discriminate the impacts of $\mathrm{DH}^{11}$ a specific instrument was developed focusing on the consequences of $\mathrm{DH}$ on oral health-related quality of life. ${ }^{8}$ The Dentine Hypersensitivity Experience Questionnaire (DHEQ) was settled to detect functional limitations, coping behaviors, emotional and social impacts caused by $\mathrm{DH}$, showing excellent reliability and validity in both a general population and a clinical sample from the United Kingdom. ${ }^{8}$ It was also responsive to changes in OHQoL. ${ }^{9}$

The original DHEQ contains 50 items on five subscales of 'restrictions', 'adaptation', 'social impact', 'emotional impact', and 'identity'. The short version (DHEQ-15) consists of 15 items arranged on the same five subscales. ${ }^{12}$ In DHEQ-15, responses are given on a seven-point Likert scale, with responses coded: 1 = 'strongly disagree', 2 = 'disagree', 3 = 'agree a little', $4=$ 'neither agree nor disagree', 5 = 'agree a little', $6=$ 'agree' and 7 = 'strongly agree'. The total score is calculated as the sum of all 15 items scores (1-7 Likert scale) per participant (possible range of 15-105). Subscale scores for each one of the five subscales is created in the same way. The proportion of impacts is calculated as the number of impacts that each participant broadly agreed ("strongly agree", "agree", "agree a little"). ${ }^{8}$ Higher DHEQ-15 scores indicate negative impact on quality of life. The DHEQ-15 has been recommended to identify people with $\mathrm{DH}$ or to evaluate $\mathrm{DH}$ treatments. ${ }^{13}$

The cross-cultural adaptation of an instrument is mandatory for the use in a new country, culture, and/or language in order to maximize the attainment of semantic, idiomatic, experiential, and conceptual equivalence between the original and the target versions. ${ }^{14}$ If the new culture has subtle differences in the living and/or has a different way of approaching a task, it would change the statistical properties of the new version. Further tests should be conducted on the psychometric properties of the adapted instrument in order to demonstrate the measurement properties needed for the intended application, such as reliability and validity. ${ }^{14}$ Therefore, the aim of the present study was to adapt and validate the DHEQ-15 for use in the Brazilian-Portuguese language.

\section{Methodology}

\section{Patient settings}

The validation study was conducted at the Periodontics Clinic of the School of Dentistry - Federal University of Minas Gerais, Belo Horizonte, Brazil.

In order to estimate the sample size, calculations were made based on the desired precision of Cronbach's alpha. ${ }^{15}$ One hundred individuals were determined to be necessary for a fifteen-item instrument to obtain a 95\% confidence interval (CI) for Cronbach's alpha about $0.934,{ }^{14}$ with a desired CI width of about 0.06 .

Participants were included if they had at least two nonadjacent sensitive teeth with a response $\geq 1$ on the Schiff scale. Individuals were excluded if they had: a) teeth with evidence of current or recent caries, b) teeth with exposed dentine but with deep, defective or facial restorations, teeth used as abutments for fixed or removable partial dentures, teeth with full crowns or veneers, orthodontic bands or cracked enamel, c) sensitive teeth with contributing aetiologies other than erosion, abrasion or recession of exposed dentine.

\section{Evaluation of dentine hypersensitivity}

The teeth were subjected to an air blast (evaporative stimulus) for $2 \mathrm{~s}$ from a $1 \mathrm{~cm}$ distance onto the buccal surface 1-2 mm coronal to the free gingival margin. The degree of pain was scored according to the Schiff cold air sensitivity scale: ${ }^{16} 0$ - subject does not respond to air stimulus; 1- subject responds to air stimulus, but does not request discontinuation of stimulus; 2- subject responds to air stimulus and requests discontinuation or moves from stimulus; 3- subject responds to air stimulus, considers stimulus to be painful, and requests discontinuation of the stimulus. Dentine hypersensitivity was assessed throughout the study by a single examiner (DWDO) who had been previously clinically trained. 


\section{Development of the Brazilian version of DHEQ-15}

The Brazilian version of the DHEQ-15 was obtained after the assessment of its conceptual, item, and semantic equivalences. The DHEQ-15 was adapted into Brazilian-Portuguese using the cross-cultural method described by Beaton et al. ${ }^{14}$ This process involved five stages:

1. First, two independent translators translated the DHEQ-15 from English to Brazilian-Portuguese. Both were native Brazilians, fluent in the English language and with background knowledge in Dentistry. Each produced a translated version of DHEQ-15;

2. These two versions were synthesized into one version. A written report carefully documenting the process, containing each of the issues addressed and how they were resolved was provided;

3. The synthesized version was back-translated from Brazilian-Portuguese to English by two professional translators fluent in Portuguese (Brazilian) but whose mother language is English. Neither was familiar with the original instrument. Each produced a written report of his back-translation. The backward translations were synthesized and compared with the original English version;

4. The translated, synthesized, and back-translated versions, as well as the written reports, were compared and discussed by an expert panel comprising two $\mathrm{PhD}$ students and two dental specialists with extensive knowledge of Oral Health Related Quality of Life assessment and biostatistics. All were fluent in both English and Portuguese. A preliminary Brazilian version of the DHEQ-15 was then produced along with a written report;

5. The preliminary Brazilian version of the DHEQ-15 was pilot tested on a convenience sample of 10 individuals who were not included for additional testing of psychometric properties. Each participant was then interviewed to enquire about any difficulties in completing the DHEQ-15 or understanding the meaning of each question or response. The expert panel discussed the findings and developed the Brazilian DHEQ-15 (Figure).

Additional testing of the final version assessed its psychometric properties. The instrument was self-administered to a sample of: 1) 100 individuals who presented with dentine hypersensitivity and completed the instrument twice, with an interval of

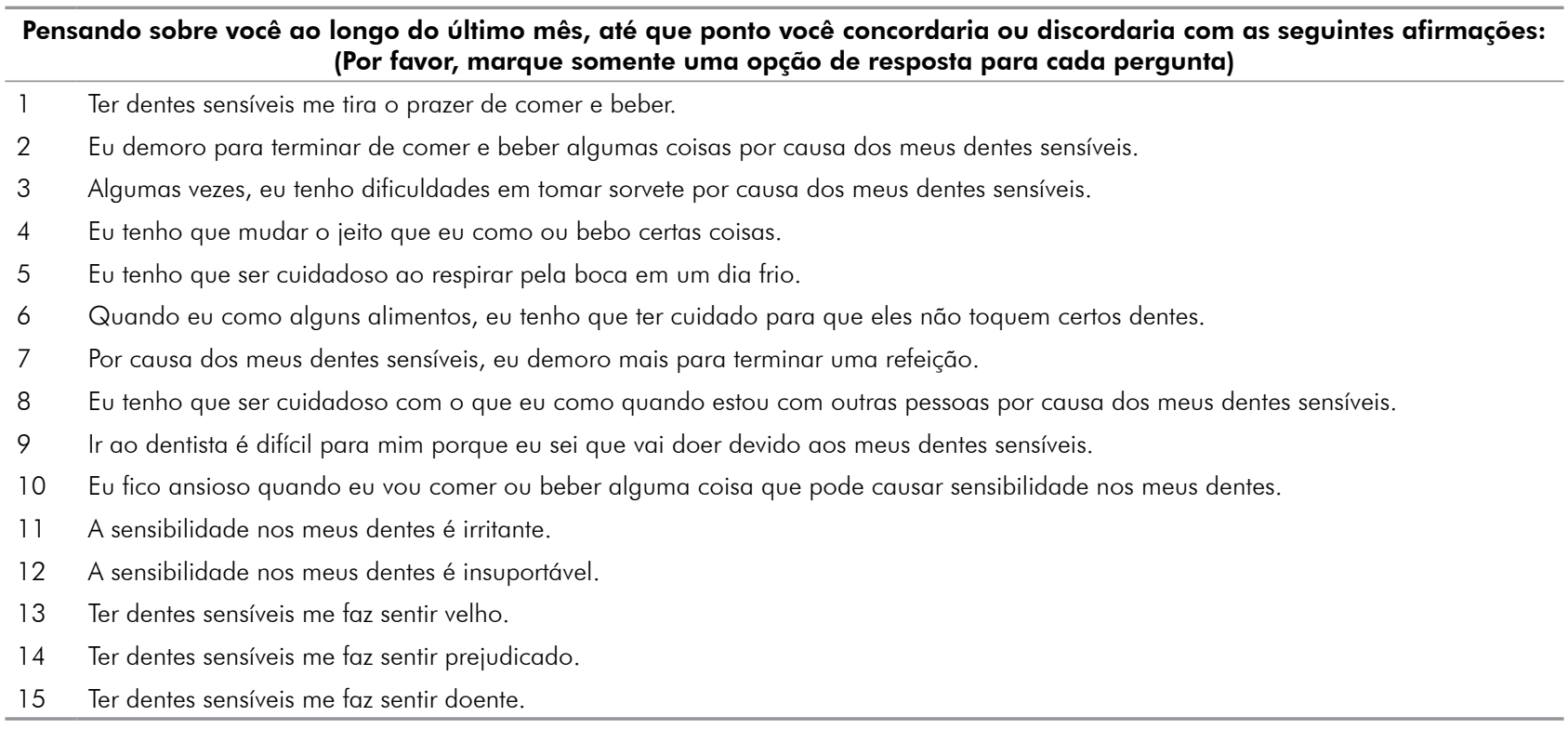

Todos itens devem ser respondidos em uma escala Likert de 7 pontos com as opções e os escores: concordo muito (7), concordo (6), concordo um pouco (5), nem concordo nem discordo (4), discordo um pouco (3), discordo (2) ou discordo muito (1).

Figure. The Brazilian version of the 15-item dentin hypersensitivity experience questionnaire (DHEQ-15). 
7-10 days, these subjects did not receive any treatment for $\mathrm{DH}$; 2) 100 individuals who did not have dentine hypersensitivity (i.e. Schiff scale $=0$ ) and completed it only once.

The total score is calculated as the sum of all 15 items scores (1-7 Likert scale) per participant (possible range of 15-105). Subscale scores for each one of the five subscales is created in the same way. The proportion of impacts is calculated as the number of impacts that each participant broadly agreed ("strongly agree", "agree", "agree a little"). ${ }^{10}$ Higher DHEQ-15 scores indicate negative impact on quality of life.

The instrument also included one item designed to assess the construct validity of the Brazilian DHEQ-15: all participants were asked to self-report their global oral health on a 6-point scale from 1 (very poor) to 6 (excellent) ${ }^{8}$

During the whole development process, the expert panel was in touch with a developer of the original DHEQ (PGR).

\section{Statistical analysis}

Analysis was performed using the Statistical Package for the Social Sciences ${ }^{\circledR}$, version 23 (IBM Corp. Armonk, NY, US). Descriptive analysis provided frequencies, means, and standard deviations.

Internal consistency was evaluated using Cronbach's alpha for multi-item subscales, each item deleted and corrected item-totals. Cronbach's alpha is a summary statistic, which captures the extent of agreement between all possible subsets of items. Values $\geq 0.70$ were considered acceptable. ${ }^{17}$ Corrected Item-Total Correlation Coefficients were obtained. Values $\geq 0.20$ were considered acceptable.

Test-retest reliability was determined by calculating intraclass correlation coefficient (ICC) using data from the 100 patients who completed the DHEQ-15 twice. The ICC was calculated based on single measured, two-way mixed, consistency model. The degree of reliability was assessed based on the following ICC values: $\leq 0.40=$ weak; $0.41-0.60=$ moderate; $0.61-0.80=$ good; and $0.81-1.00=$ excellent. ${ }^{18}$ The value of ICC was used to estimate the standard error of measurement (SEM), and thereafter, to estimate the smallest detectable change (SDC) (95\% level of confidence).
Convergent validity was tested through investigating the correlation (Spearman correlation) between DHEQ-15 subscale scores and global rating of oral health. The underlying hypothesis was that participants who rated their overall oral health status as poor would score higher on the DHEQ-15. The correlation values are considered to indicate poor correlation when $<0.20$, to indicate fair correlation when $0.21-0.40$, to signify good correlation when $0.41-0.60$, to indicate very good correlation when $0.61-0.80$, and to indicate excellent correlation when $>0.81 .^{13}$ It was expected a very good and/or excellent negative correlation between these variables.

Discriminative validity was tested through the Mann-Whitney test by comparing the difference in subscale and total scores between participants with and without dentine hypersensitivity. The hypothesis was that participants with $\mathrm{DH}$ would have higher DHEQ-15 scores (indicating worse OHRQoL).

Cross-cultural validity was investigated by confirmatory factor analysis (CFA). It was hypothesized that the five dimensions of original instrument could be replicated in this analysis. It was conducted CFA on the raw scores using the ML estimator in Mplus, Version 7.1 (Muthén \& Muthén, CA, US). It was used the chi-squared-to-df ratio of 3 and SRMR $<.08$, and CFI $>.95$ as cutoffs for excellent fit and CFI $>.90$ for acceptable fit.

\section{Ethical principles}

The study protocol was approved by the Ethical Research Committee of the Federal University of Minas Gerais (CAAE \#50173115.5.0000.5149). All participants were informed about the objectives of the study and signed the informed consent form prior to data collection. The present study was also conducted in accordance with the Helsinki Declaration of 1975, as revised in 2013.

\section{Results}

The evaluations by the expert panel indicated that there was semantic equivalence in the translated items, idiomatic equivalence between the two translations, and an absence of translation difficulties. The assessment of semantic equivalence was performed between the items from the back-translated synthesis version and the items from the original version. The panel testing suggested two modifications. The original term 
"sensations in my teeth" was replaced by "sensitive teeth" in the Brazilian DHEQ-15. In the item 5, the expression "how I breathe" was complemented by the term "through the mouth"; in Brazilian version it reads "how I breathe through the mouth". Moreover, the panel understood the scales and reported no consistent problems in the use of DHEQ-15.

Two hundred individuals aged from 18 to 67 years participated in the study (Table 1). Thirty-eight (19.0\%) were classified as degree 1 hypersensitivity; 33 (16.5\%) as degree 2; 29 (14.5\%) degree 3; and, 100 (50.0\%) participants had no dentine hypersensitivity $($ Schiff scale $=0)($ Table 1$)$.

All instruments were completed with no missing values. The average time to complete the questionnaire was $5( \pm 3)$ minutes. The mean value of the global rating of oral health question was 4.17 ( \pm 1.38$)$. The mean score for the total scale in the study population was 52.57 ( \pm 21.93 ). Table 2 shows the mean and standard deviation (SD) for subscale and total scores of the Brazilian version of DHEQ-15.

Test-retest reliability was calculated for 100 participants who completed DHEQ 7-10 days apart. Test-retest reliability was evaluated using ICCs that

Table 1. Characteristics of the participants of the study.

\begin{tabular}{lcc}
\hline Variables & $n$ & $\%$ \\
\hline Gender & & \\
Male & 69 & 34.5 \\
Female & 131 & 65.5 \\
Schiff scale & & \\
0 & 100 & 50.0 \\
1 & 38 & 19.0 \\
2 & 33 & 16.5 \\
3 & 29 & 14.5 \\
& Mean & SD \\
Age & 30.4 & 12.7 \\
\hline
\end{tabular}

ranged from 0.781 to 0.913 , for restrictions and social impacts, respectively. The ICC for the total score was 0.959 ( $\mathrm{IC}_{95}: 0.940-0.972$ ) (Table 2). The ICC values for the Brazilian DHEQ-15 indicated good to excellent agreement. The lowest and highest SEM value was 1.403 (social impact) and 3.436 (total score), respectively. The SDC ranged from 3.891 (social impact) to 9.526 (total score).

The Cronbach's Alpha Coefficient was obtained for the total score and the different domains (Table 2). The alpha for the total score was $0.945\left(\mathrm{IC}_{95}: 0.933-0.955\right)$, and for the domains ranged from 0.779 for 'adaptation' to 0.879 for 'emotional impact'. All domains and the total score exceeded the minimum reliability standard of 0.70 . The values of the corrected item - total correlation were higher than 0.560 , and ranged from 0.560 (item 13) to 0.821 (item 8 ) (Table 2). The alpha if item deleted ranged from 0.938 to 0.944 (Table 3).

Total and domains scores of the Brazilian DHEQ15 had significantly negative correlations with global oral health status $\left(r_{\mathrm{s}}\right.$ ranged from -0.615 (social impact) to -0.546 (identity), $\mathrm{p}<0.001$, indicating good convergent validity (Table 4$)$.

Table 5 displays means, standard deviations, and Mann-Whitney test results of the responses on each domain of DHEQ-15 in patients with and without $\mathrm{DH}$. The mean value of the total score of DHEQ-15 was $67.88( \pm 16.97)$ and $37.27( \pm 14.33)$ in patients with and without $\mathrm{DH}$, respectively. Total and domains scores were higher in participants with $\mathrm{DH}(\mathrm{p}<0.001)$.

The CFA model showed an acceptable fit to the data, with a chi-squared-to-df ratio of 3.0 (chi-squared $=$ 266.34, $\mathrm{df}=88, \mathrm{p}<.001$ ), SRMR = 0.049, and CFI $=0.92$. The CFA confirmed that all items had substantial and statistically significant $(\mathrm{p}<.001)$ loadings from the respective factors ( $b=0.65$ to 0.89 ) (Table 6).

Table 2. Mean score, test retest reliability, and internal consistency for the subscales and the total sum of the Brazilian DHEQ-15.

\begin{tabular}{lcccccccc}
\hline Subscale & Mean & SD & ICC & $\mathrm{Cl}_{95}$ (LE-UE) & $p$-value & SEM & SDC & Cronbach's $\alpha$ \\
\hline Restrictions & 13.09 & 5.12 & 0.781 & $0.691-0.847$ & $<0.001$ & 1.677 & 4.649 & 0.812 \\
Adaptation & 11.20 & 5.10 & 0.852 & $0.787-0.898$ & $<0.001$ & 1.420 & 3.936 & 0.779 \\
Social impact & 9.58 & 5.09 & 0.913 & $0.873-0.940$ & $<0.001$ & 1.403 & 3.891 & 0.853 \\
Emotional impact & 10.43 & 5.36 & 0.888 & $0.838-0.923$ & $<0.001$ & 1.423 & 3.945 & 0.879 \\
Identity & 8.27 & 4.52 & 0.814 & $0.736-0.871$ & $<0.001$ & 2.063 & 5.720 & 0.823 \\
Total score & 52.57 & 21.93 & 0.959 & $0.940-0.972$ & $<0.001$ & 3.436 & 9.526 & 0.945 \\
\hline
\end{tabular}

LE: lower extremity.; UE: upper extremity; SEM: standard error of measurement; SDC: smallest detectable change. 
Cross-cultural adaptation of the Brazilian version of the Dentine Hypersensitivity Experience Questionnaire

Table 3. Internal consistency of the Brazilian version of DHEQ-15.

\begin{tabular}{lccc}
\hline Item & Scale mean if item deleted & Corrected Item-Total correlation & Cronbach's Alpha if item deleted \\
\hline Item 1 & 48.07 & 0.611 & 0.943 \\
Item 2 & 48.59 & 0.758 & 0.940 \\
Item 3 & 47.98 & 0.667 & 0.942 \\
Item 4 & 48.44 & 0.656 & 0.942 \\
Item 5 & 49.31 & 0.651 & 0.942 \\
Item 6 & 48.78 & 0.739 & 0.940 \\
Item 7 & 49.16 & 0.814 & 0.938 \\
Item 8 & 49.50 & 0.821 & 0.938 \\
Item 9 & 49.49 & 0.685 & 0.941 \\
Item 10 & 49.07 & 0.808 & 0.938 \\
Item 11 & 48.66 & 0.791 & 0.939 \\
Item 12 & 49.57 & 0.803 & 0.939 \\
Item 13 & 50.21 & 0.560 & 0.944 \\
Item 14 & 49.07 & 0.677 & 0.942 \\
Item 15 & 50.18 & 0.564 & 0.944 \\
\hline
\end{tabular}

Table 4. Correlation between DHEQ-15 and global rating of oral health (convergent validity).

\begin{tabular}{lcc}
\hline \multirow{2}{*}{ Variable } & \multicolumn{2}{c}{ Oral health rating } \\
\cline { 2 - 3 } & $r_{s}$ & $p$-value \\
\hline Restrictions & -0.559 & $<0.001$ \\
Adaptation & -0.561 & $<0.001$ \\
Social impact & -0.615 & $<0.001$ \\
Emotional impact & -0.603 & $<0.001$ \\
Identity & -0.546 & $<0.001$ \\
Total score & -0.662 & $<0.001$ \\
\hline
\end{tabular}

Table 5. Association between DHEQ-15 and dentin hypersensitivity (discriminant validity).

\begin{tabular}{lccccc}
\hline \multirow{2}{*}{ Variable } & \multicolumn{3}{c}{ DH present } & \multicolumn{3}{c}{ DH absent } & \multirow{2}{*}{ p-value } \\
\cline { 2 - 6 } & Mean & SD & Mean & SD & \\
\hline Restrictions & 15.96 & 3.58 & 10.22 & 4.83 & $<0.001$ \\
Adaptation & 14.74 & 3.69 & 7.66 & 3.66 & $<0.001$ \\
Social impact & 12.90 & 4.75 & 6.26 & 2.71 & $<0.001$ \\
Emotional impact & 14.07 & 4.25 & 6.79 & 3.61 & $<0.001$ \\
Identity & 10.21 & 4.78 & 6.34 & 3.25 & $<0.001$ \\
Total score & 67.88 & 16.97 & 37.27 & 14.33 & $<0.001$ \\
\hline
\end{tabular}

\section{Discussion}

$\mathrm{DH}$ is part of everyday life for many people and can compromise their well-being. 19, 20 The DHEQ-15 instrument was developed in order to quantify the effects of DH on everyday life. ${ }^{8}$ It was aimed to provide the first cross-cultural adaptation of the DHEQ-15 in Brazil, and the findings showed the reliability and
Table 6. Factor loadings of the confirmatory factor analysis.

\begin{tabular}{cc}
\hline Variable & Standardized loading \\
\hline Restriction & \\
Item 1 & 0.653 \\
Item 2 & 0.892 \\
Item 3 & 0.766 \\
Adaptation & \\
Item 4 & 0.712 \\
Item 5 & 0.717 \\
Item 6 & 0.847 \\
Social impact & \\
Item 7 & 0.856 \\
Item 8 & 0.868 \\
Item 9 & 0.737 \\
Emotional impact & \\
Item 10 & 0.848 \\
Item 1 1 & 0.851 \\
Item 12 & 0.858 \\
Identity & \\
Item 13 & 0.709 \\
Item 14 & 0.882 \\
Item 15 & 0.709 \\
\hline
\end{tabular}

validity of the DHEQ-15 to measure the impact of $\mathrm{DH}$ in the Brazilian population.

Psychometric instruments, like DHEQ-15, are scales that permit the recording of the reports of individuals in a standardized and reproducible way. They can be divided into two groups: those completed by the observer (rating scales) and those completed by the person her/himself (self-report scales). While the former present problems regarding 
the observer's experience, the latter demand greater individual cooperation. ${ }^{21}$ The DHEQ-15 is a self-report instrument, and the Brazilian version showed it could be completed quickly and easily which may increase individual cooperation when using it.

Most OHRQoL scales were developed in western countries and, therefore, require a cross-cultural adaptation in order to be used in different countries. ${ }^{14,21}$ The cross-cultural adaptation and validation of the DHEQ-15 was conducted following guidelines for this purpose. ${ }^{14,22}$ DHEQ-15 has also been adapted and validated into the Chinese language, ${ }^{13}$ using the same process employed here. The adoption of a single method for the adaptation of a same instrument in various countries allows the adjustment and validity between the translated versions. Also, the adaptations emphasize the importance for a standardized process.

After the back-translation process, the synthesized version was evaluated by the developer of the instrument. This may have enhanced the equivalence between the original and the translated versions. The expert panel concluded that both pairs of translation/ back-translation achieved adequate equivalence to the original instrument regarding the semantic aspects. Pilot testing of a translated instrument among participants in order to evaluate the items and the response forms for clarity also enhanced the quality of the final version of the translation. ${ }^{23}$ The suggestions of the panel were accepted by the expert panel, and modifications were made to meet the current vocabulary and culture of Brazilians.

The Cronbach's alpha is the most widely used method for estimating internal consistency reliability in applied research, ${ }^{24}$ and should be performed to all new measurement methods. ${ }^{25}$ It measures the extent to which the items in the test measure the same construct. ${ }^{26}$ An alpha value greater than 0.70 is considered acceptable for measures to be used in groups. ${ }^{17}$ The present Cronbach's alpha showed that on average $94.5 \%$ of the DHEQ-15 score may be explained by 15 -interitem covariances. Thus, the present 15 items are highly interrelated. In the present study, the Cronbach's alpha for DHEQ-15 total scores was slightly higher than both English $(\alpha=0.906)^{12}$ and Chinese $(\alpha=0.934)^{13}$ DHEQ-15 versions. All Cronbach's alpha if item deleted were higher than 0.9 , and as a good result of this excellent internal consistency, none item needed to be excluded. However, high Cronbach's alpha does not necessarily indicate a high level of consistency between the instrument items. ${ }^{27}$ High values may be related to redundancy of the items, compromising content validity, since an item set in the instrument can measure something similar to some of the other items. ${ }^{28}$

Test-retest reliability is a basic aspect in the examination of scientific measurements of physiological or psychological constraints. The ICC is a common parameter or index used to estimate measurement reliabilities induced by human errors. ${ }^{18}$ An instrument has temporal stability (test-retest reliability) if repeated measurements are obtained in constant conditions, and give the same or compatible results, assuming that there was no change in the characteristics of what is being measured. ${ }^{29,30}$ In order to verify temporal stability, the time between test and retest should be long enough to prevent recall, but short enough to ensure none clinical changes. A period of 1 to 2 weeks is often considered appropriate as was the case here. ${ }^{31}$ During this time, individuals did not receive any DH treatment. The ICC for total score was higher than the Chinese version $(\mathrm{ICC}=0.894),{ }^{13}$ and close to the English version, which reported ICCs above 0.9.12 This finding supports that any reliable examination/ procedure would need to produce similar results regardless of time, environment, or examiner. ${ }^{29}$ The ICCs for domains and total score of the Brazilian DHEQ-15 were above 0.7 indicating that measures are stable over time. The present results show that the Brazilian DHEQ-15 may be considered a reliable and stable instrument.

Reliability is of central importance in assessment of agreement between measurements in successive sessions..$^{32}$ Reliability depends on both ICC and SEM of subjects taking an assessment. The SEM is the amount of error that can be attributed to measurement error, and it is an adequate calculation if one needs a general statistic for describing the accuracy of the score achieved by a randomly chosen subject. ${ }^{33}$ The smaller the SEM, the more accurate are the assessments that are being made. The present findings showed high ICCs and small SEMs relative to means, indicating a more accurate instrument, which is a desirable 
outcome. In addition, random measurement error exists in all assessments. If the measurement error of an instrument is not determined, the interpretability of the test scores is limited..$^{32}$ It was used SDC in order to calculate the random measurement error. The SDC is the smallest threshold of a change score that is beyond random error at a certain confidence level. ${ }^{32,33}$ The present research showed small SDC values, they indicated that low differences between consecutive assessments of a single patient are able to announce a real change beyond random error.

The construct validity of the translated DHEQ-15 was evaluated by discriminative, convergent and cross-cultural validity. Instruments about individuals' health and functioning filled out by the individual should be validated to ensure that they measure the construct that they aim to measure (validity). ${ }^{34}$

The convergent validity reflects whether the scores of the instrument under study "make sense" in relation to the scores of other related instruments. ${ }^{34} \mathrm{~A}$ standard global rating of oral health was employed to examine convergent validity, since both the instrument and the question measure the participants' oral health. Participants with higher DHEQ-15 scores had rated their overall oral health as worse. High DHEQ-15 scores indicate more negative impact of $\mathrm{DH}$ on daily life. Convergent validity is generally considered adequate if a correlation with an instrument measuring the same construct is $>0.50 .{ }^{31}$ All correlation coefficient were higher than 0.54 , confirming the convergent validity of the translated DHEQ-15. Both the Chinese and the English DHEQ-15 had good convergent validity. ${ }^{12,13}$

Discriminant validity requires the contrast of measures of constructs in the same conceptual domain. ${ }^{35}$ The DHEQ-15 scores of participants with DH were significantly higher than of those without. This difference should be viewed as evidence for discriminant validity and indicates that groups (with and without $\mathrm{DH}$ ) are distinct from each another. The discriminative capacity of this new condition-specific instrument for $\mathrm{DH}$ is much higher than previous instruments could show. ${ }^{8}$

CFA was recommended to investigate the cross-cultural validity in cross-cultural studies according to the COSMIN (Consensus-based Standards for the selection of health status Measurement Instruments). ${ }^{36}$ Cross-cultural validity refers to the degree to which the performance of the items on an adapted instrument are an adequate reflection of the performance of the items of the original version. ${ }^{37}$ Considering the conceptual foundation and results of the original ${ }^{12}$ study, five dimensions was suitable for the DHEQ-15. The CFA employed herein added a level of statistical precision and confirmed the Brazilian instrument domains reflect the same domains of the original version.

DH cannot be considered a disease, and its treatment is often determined by symptoms, mainly the pain, and the experience of $\mathrm{DH}$ can be unpleasant for the individual. ${ }^{20}$ Considering that $\mathrm{DH}$ is able to promote behavioral changes and negatively influence oral health-related quality of life, ${ }^{8,9}$ clinicians and researchers should use this questionnaire as ultimate outcome, ${ }^{38}$ and not only as complementary finding. The impact of DH on quality of life measured by this instrument can be used as a parameter for either deciding to initiate the treatment or even evaluating the effectiveness of the treatment.

Although well conducted, limitations should be present in the present study. For example, the responsiveness of the Brazilian version of DHEQ-15 was not verified, as this would require longitudinal data. Moreover, a judgment sampling from a clinical population was used. Further longitudinal studies are needed to confirm the responsiveness of the DHEQ-15 in the general Brazilian population.

\section{Conclusion}

The present study provided evidence supporting the cross-cultural validity of a Brazilian version of DHEQ-15 that can be recommended to evaluate the impact of DH on quality of life among Brazilians.

\section{Acknowledgments}

We would like to thank to doctoral student Yang DU (University of Illinois) for the statistical support. The work was supported by the Foundation for Research Support of the State of Minas Gerais (FAPEMIG), the National Council for Scientific and Technological Development $(\mathrm{CNPq})$, and the Coordination for Improvement of Higher Education Personnel (CAPES). The authors declare that they have no conflict of interest. 


\section{References}

1. Oliveira DWD, Marques DP, Aguiar-Cantuária IC, Flecha OD, Gonçalves PF. Effect of surgical defect coverage on cervical dentin hypersensitivity and quality of life. J Periodontol. 2013 Jun;84(6):768-75. https://doi.org/10.1902/jop.2012.120479

2. West NX, Sanz M, Lussi A, Bartlett D, Bouchard P, Bourgeois D. Prevalence of dentine hypersensitivity and study of associated factors: a European population-based cross-sectional study. J Dent. 2013 Oct;41(10):841-51. https://doi.org/10.1016/j.jdent.2013.07.017

3. Fischer C, Fischer RG, Wennberg A. Prevalence and distribution of cervical dentine hypersensitivity in a population in Rio de Janeiro, Brazil. J Dent. 1992 Oct;20(5):272-6. https://doi.org/10.1016/0300-5712(92)90043-C

4. Scaramucci T, Anfe TEA, Ferreira SS, Frias AC, Sobral MA. Investigation of the prevalence, clinical features, and risk factors of dentin hypersensitivity in a selected Brazilian population. Clin Oral Investig. 2014;18(2):651-7. https://doi.org/10.1007/s00784-013-1008-1

5. Costa RS, Rios FS, Moura MS, Jardim JJ, Maltz M, Haas AN. Prevalence and risk indicators of dentin hypersensitivity in adult and elderly populations from Porto Alegre, Brazil. J Periodontol. 2014 Sep;85(9):1247-58. https://doi.org/10.1902/jop.2014.130728

6. Mehta P, Vimala N, Mandke L. An insight into dentin desensitizing agents —in vivo study. Indian J Dent Res. 2013 SepOct;24(5):571-4. https://doi.org/10.4103/0970-9290.123369

7. Patel RR, Richards PS, Inglehart MR. Periodontal health, quality of life, and smiling patterns: an exploration. J Periodontol. 2008 Feb;79(2):224-31. https://doi.org/10.1902/jop.2008.070344

8. Boiko OV, Baker SR, Gibson BJ, Locker D, Sufi F, Barlow AP et al. Construction and validation of the quality of life measure for dentine hypersensitivity (DHEQ). J Clin Periodontol. 2010 Nov;37(11):973-80. https://doi.org/10.1111/j.1600-051X.2010.01618.x

9. Baker SR, Gibson BJ, Sufi F, Barlow A, Robinson PG. The Dentine Hypersensitivity Experience Questionnaire: a longitudinal validation study. J Clin Periodontol. 2014 Jan;41(1):52-9. https://doi.org/10.1111/icpe.12181

10. Goh V, Corbet EF, Leung WK. Impact of dentine hypersensitivity on oral health-related quality of life in individuals receiving supportive periodontal care. J Clin Periodontol. 2016 Jul;43(7):595-602. https://doi.org/10.1111/icpe.12552

11. Bekes K, John MT, Schaller HG, Hirsch C. Oral health-related quality of life in patients seeking care for dentin hypersensitivity. J Oral Rehabil. 2009 Jan;36(1):45-51. https://doi.org/10.1111/j.1365-2842.2008.01901.x

12. Machuca C, Baker SR, Sufi F, Mason S, Barlow A, Robinson PG. Derivation of a short form of the Dentine Hypersensitivity Experience Questionnaire. J Clin Periodontol. 2014 Jan;41(1):46-51. https://doi.org/10.1111/jcpe.12175
13. He SL, Wang JH. Reliability and validity of the Chinese version of the short form of the Dentine Hypersensitivity Experience Questionnaire (DHEQ-15). Qual Life Res. 2015 Jun;24(6):1465-9. https://doi.org/10.1007/s11136-014-0856-8

14. Beaton DE, Bombardier C, Guillemin F, Ferraz MB. Guidelines for the process of cross-cultural adaptation of self-report measures. Spine. 2000 Dec;25(24):3186-91. https://doi.org/10.1097/00007632-200012150-00014

15. Bonett DG, Wright TA. Cronbach's alpha reliability:interval estimation, hypothesis testing, and sample size planning. In., vol. 36. J Organ Behav. 2015;36(1):3-15. https://doi.org/10.1002/job.1960

16. Schiff T, Dotson M, Cohen S, De Vizio W, McCool J, Volpe A Efficacy of a dentifrice containing potassium nitrate, soluble pyrophosphate, PVM/MA copolymer, and sodium fluoride on dentinal hypersensitivity: a twelve-week clinical study. J Clin Dent. 1994;5(Spec No):87-92.

17. Bland JM, Altman DG. Cronbach's alpha. BMJ. 1997 Feb;314(7080):572-572. https://doi.org/10.1136/bmj.314.7080.572

18. Li L, Zeng L, Lin ZJ, Cazzell M, Liu H. Tutorial on use of intraclass correlation coefficients for assessing intertest reliability and its application in functional near-infrared spectroscopy-based brain imaging. J Biomed Opt. 2015 May;20(5):50801. https://doi.org/10.1117/1.JBO.20.5.050801

19. Lima TC, Vieira-Barbosa NM, Grasielle de Sá Azevedo C, de Matos FR, Douglas de Oliveira DW, de Oliveira ES et al. Oral Health-Related Quality of Life Before and After Treatment of Dentin Hypersensitivity With Cyanoacrylate and Laser. J Periodontol. 2017 Feb;88(2):166-72. https://doi.org/10.1902/jop.2016.160216

20. Pashley DH. How can sensitive dentine become hypersensitive and can it be reversed? J Dent. 2013 Jul;41 Suppl 4:S49-55. https://doi.org/10.1016/S0300-5712(13)70006-X

21. Callias M. Handbook of research methods in clinical psychology. J Child Psychol Psychiatry. 2005;46(5):559. https://doi.org/10.1111/i.1469-7610.2004.01473_1.x

22. Guillemin F, Bombardier C, Beaton D. Cross-cultural adaptation of health-related quality of life measures: literature review and proposed guidelines. J Clin Epidemiol. 1993 Dec;46(12):1417-32. https://doi.org/10.1016/0895-4356(93)90142-N

23. Sousa VD, Roijanasrirat W. Translation, adaptation and validation of instruments or scales for use in cross-cultural health care research: a clear and user-friendly guideline. J Eval Clin Pract. 2011 Apr;17(2):268-74. https://doi.org/10.1111/j.1365-2753.2010.01434.x

24. Trizano-Hermosilla I, Alvarado JM. Best alternatives to Cronbach's alpha reliability in realistic conditions: congeneric and asymmetrical measurements. Front Psychol. 2016 May;7(7):769. https://doi.org/10.3389/fpsyg.2016.00769 
- Cross-cultural adaptation of the Brazilian version of the Dentine Hypersensitivity Experience Questionnaire

25. McCrae RR, Kurtz JE, Yamagata S, Terracciano A. Internal consistency, retest reliability, and their implications for personality scale validity. Pers Soc Psychol Rev. 2011 Feb;15(1):28-50. https://doi.org/10.1177/1088868310366253

26. Sijtsma K. On the Use, the misuse, and the very limited usefulness of Cronbach's alpha. psychometrika. 2009 Mar;74(1):107-20. https://doi.org/10.1007/s11336-008-9101-0

27. Tavakol M, Dennick R. Making sense of Cronbach's alpha. Int J Med Educ. 2011 Jun;2:53-5. https://doi.org/10.5116/ijme.4dfb.8dfd

28. Santos KO, Carvalho FM, Araújo TM. Internal consistency of the self-reporting questionnaire-20 in occupational groups. Rev Saude Publica. 2016;50(0):6. https://doi.org/10.1590/S1518-8787.2016050006100

29. Lee KM, Lee J, Chung CY, Ahn S, Sung KH, Kim TW et al. Pitfalls and important issues in testing reliability using intraclass correlation coefficients in orthopaedic research. Clin Orthop Surg. 2012 Jun;4(2):149-55. https://doi.org/10.4055/cios.2012.4.2.149

30. Koo TK, Li MY. A Guideline of Selecting and Reporting Intraclass Correlation Coefficients for Reliability Research. J Chiropr Med. 2016 Jun;15(2):155-63. https://doi.org/10.1016/i.jcm.2016.02.012

31. Terwee CB, Bot SD, Boer MR, Windt DA, Knol $\mathrm{DL}$, Dekker J et al. Quality criteria were proposed for measurement properties of health status questionnaires. J Clin Epidemiol. 2007 Jan;60(1):34-42. https://doi.org/10.1016/i.jclinepi.2006.03.012

32. Huang SL, Hsieh CL, Wu RM, Lu WS. Test-retest reliability and minimal detectable change of the Beck Depression Inventory and the Taiwan Geriatric Depression Scale in patients with
Parkinson's disease. PLoS One. 2017 Sep;12(9):e0184823. https://doi.org/10.1371/journal.pone.0184823

33. Tighe J, McManus IC, Dewhurst NG, Chis L, Mucklow $J$. The standard error of measurement is a more appropriate measure of quality for postgraduate medical assessments than is reliability: an analysis of MRCP(UK) examinations. BMC Med Educ. 2010 Jun;10(1):40. https://doi.org/10.1186/1472-6920-10-40 PM

34. Abma IL, Rovers M, Wees PJ. Appraising convergent validity of patient-reported outcome measures in systematic reviews: constructing hypotheses and interpreting outcomes. BMC Res Notes. 2016 Apr;9(9):226. https://doi.org/10.1186/s13104-016-2034-2PMID:27094345

35. Strauss ME, Smith GT. Construct validity: advances in theory and methodology. Annu Rev Clin Psychol. 2009;5(1):1-25. https://doi.org/10.1146/annurev.clinpsy.032408.153639

36. Mokkink LB, Terwee CB, Patrick DL, Alonso J, Stratford $\mathrm{PW}, \mathrm{Knol} \mathrm{DL}$ et al. The COSMIN checklist for assessing the methodological quality of studies on measurement properties of health status measurement instruments: an international Delphi study. Qual Life Res. 2010 May;19(4):539-49. https://doi.org/10.1007/s11136-010-9606-8

37. Mokkink LB, Terwee CB, Gibbons E, Stratford PW, Alonso J, Patrick DL et al. Inter-rater agreement and reliability of the COSMIN (COnsensus-based Standards for the selection of health status Measurement Instruments) checklist. BMC Med Res Methodol. 2010 Sep;10(1):82. https://doi.org/10.1186/1471-2288-10-82

38. Apers S, Luyckx K, Moons P. Is quality of life the ultimate outcome parameter? Eur J Cardiovasc Nurs. 2013 Dec;12(6):502-4. https://doi.org/10.1177/1474515113512735 